\title{
Violência escolar: percepções de alunos e professores de uma escola pública
}

\author{
Jaqueline Portella Giordani \\ Colégio de Aplicação da UFRGS - Porto Alegre - RS - Brasil \\ Fernando Seffner \\ Universidade Federal do Rio Grande do Sul - Porto Alegre - RS - Brasil \\ Débora Dalbosco Dell'Aglio \\ Universidade Federal do Rio Grande do Sul - Porto Alegre - RS - Brasil
}

\begin{abstract}
Resumo
Este estudo investigou a percepção de estudantes e de professores acerca da violência no espaço escolar. Participaram 16 professores e 60 alunos de uma escola pública de Porto Alegre/RS. Foram realizados grupos focais, sendo realizados dois grupos de alunos e um grupo de professores. A partir da análise de conteúdo foram estabelecidas quatro categorias discursivas: Violência entre pares, Violência entre alunos e professores, Violência extramuros e Ações de enfrentamento. A violência escolar foi descrita como multifacetada, ocorrendo nas formas verbal e física. Violência intra e extrafamiliar foram percebidas como relacionadas às ocorrências intraescolares. Houve diferenças nas discussões em cada grupo; entretanto, as ações da direção da escola foram pontuadas por todos como relevantes para a resolução dos conflitos. Destaca-se a necessidade de projetos de intervenção que focalizem as relações sociais entre os adolescentes e a formação dos professores e equipe diretiva para atuação nos casos de conflito.
\end{abstract}

Palavras-chave: Violência escolar; grupos focais; escola.

\section{School violence: perceptions of students and teachers of a public school}

\begin{abstract}
This study investigated the perception of students and teachers about the violence in school space. The participants were 16 teachers and 60 students from a public school in Porto Alegre / RS. Focal groups were held, with two groups of students and one group of teachers. From the content analysis, four discursive categories were established: Peer violence, Violence between students and teachers, Violence outside the walls, and Coping actions. School violence was described as multifaceted, occurring in verbal and physical forms. Intra and extrafamiliar violence were perceived as related to intra-school occurrences. There were differences in the discussions in each group, however the actions of the school management were scored by all as relevant for the resolution of the conflicts. It is important to emphasize the need for intervention projects that focus on the social relations among adolescents and the training of teachers and the management team for action in conflict cases.
\end{abstract}

Keywords: school violence; Focus groups; school.

\section{Violencia escolar: percepciones de alumnos y profesores de una escuela pública}

\section{Resumen}

Este estudio investigó la percepción de estudiantes y de profesores acerca de la violencia en el espacio escolar. Participaron 16 profesores y 60 alumnos de una escuela pública de Porto Alegre/RS. Se realizaron grupos focales, siendo realizados dos grupos de alumnos y un grupo de profesores. A partir del análisis de contenido se estableció cuatro categorías discursivas: Violencia entre pares, Violencia entre alumnos y profesores, Violencia extramuros, y Acciones de enfrentamiento. La violencia escolar fue descripta como polifacético, sucediendo en las formas verbal y física. Violencia intra y extra familiar fueron percibidas como relacionadas a los sucesos intraescolares. Hubo diferencias en las discusiones en cada grupo, sin embargo. Las acciones de la dirección de la escuela fueron apuntadas por todos como relevantes para la resolución de los conflictos. Se destaca la necesidad de proyectos de intervención que focalicen las relaciones sociales entre los adolescentes y la formación de los profesores y equipo directiva para actuación en los casos de conflicto.

Palabras clave: violencia escolar; grupos focales; escuela. 


\section{Introdução}

Os adolescentes estão sujeitos a maior exposição à violência familiar e comunitária do que outras faixas etárias (UNICEF, 2012a), e a violência na adolescência se constitui em grave problema de saúde pública, que pode ser observado em todos os contextos de inserção - seja em famílias ou instituições (Braga \& Dell'Aglio, 2012). Além disso, também as instituições criadas no intuito de educar e proteger os adolescentes, como as escolas, podem se constituir como espaços de violação de seus direitos (Fonseca, Sena, Santos, Dias, \& Costa, 2013), retirando a cidadania a quem deviam conceder. As violências no espaço escolar possuem diferentes denominações de acordo com a sua natureza: violência na escola, estabelecida nas relações sociais dentro desse espaço; violência da escola, que é violência simbólica estabelecida por meio de exclusão, discriminação e dominação pelo uso de poder; e a violência contra a escola, que se dá pela desvalorização social da instituição escolar e da carreira docente (Ristum, 2010). Neste estudo serão consideradas todas essas ramificações como expressões da violência escolar.

As instituições escolares têm sido ambientes em que práticas excludentes e violentas contra a população jovem também se efetuam (UNICEF, 2012a). Em pesquisas brasileiras a violência na escola é reconhecida pelos estudantes como multifacetada, sendo percebida em ações físicas contra si e contra o outro e agressão física e agressão verbal entre professor-aluno (Souza, 2012; Melo, Barros, \& Almeida, 2011). Nas escolas francesas, Debarbieux (2001) verificou que alunos e professores indicaram mais a falta de respeito nas relações do que as agressões físicas como forma prevalente de violência nas escolas. A pesquisa de Grossi e Santos (2012) realizada através de grupos focais com estudantes de Porto Alegre/RS indicou que a violência escolar tem se manifestado por meio de intolerância, agressões físicas e ameaças.

A respeito da relação professor-aluno, há de se considerar a violência estabelecida entre esses atores, que muitas vezes não é fácil de ser constatada, pois geralmente ocorre por meio de abusos no relacionamento interpessoal. As diferenças geracionais carregam consigo diferenças de autoridade (pessoal e institucional), o que na relação pedagógica pode imprimir-se em uma relação de abuso de autoridade. Assim, tanto as violências simbólicas e psicológicas contra os alunos devem ser focalizadas no contexto da violência escolar (Abramovay, 2002), como também a vitimização dos professores neste ambiente (Souza, 2012; Rocha \& cols., 2012), tanto direta quanto indiretamente.

A violência na escola pode provocar consequências diversas ao desenvolvimento saudável dos adolescentes, tanto vítimas quanto agressores. Estar exposto a situações de agressividade pode causar prejuízos ao desenvolvimento escolar, pessoal e social do adolescente (Benetti, Schwartz, Soares, Macarena, \& Patussi, 2014; Grossi \& Santos, 2009). A vitimização na escola está ligada ao aumento de índices de danos à saúde, cognitivos, psicossociais e mentais, in- cluindo depressão e suicídio (Winsper, Lereya, Zanarini, \& Wolke, 2012), sendo que os adolescentes vítimas ou agressores podem apresentar cerca de cinco vezes mais chances de ter sintomas depressivos do que os outros estudantes (Forlim, Stelko-Pereira, \& Williams, 2014).

A violência escolar é objeto de preocupação social crescente que tem assumido um caráter sistemático e que provoca efeitos no desenvolvimento das vítimas e nos agressores. Vários autores têm sugerido que para uma maior compreensão do fenômeno e para que sejam propostas ações de enfrentamento à violência no âmbito da escola é importante que se estude a concepção que os atores escolares (alunos e professores) têm acerca da violência escolar (Debarbieux, 2001; Lourenço, Pereira, Paiva, \& Gebara, 2009). Sendo assim, este estudo buscou analisar a violência escolar como um fenômeno social complexo e multifacetado, ao mesmo tempo individual, social e político, tendo como objetivo geral investigar a percepção de adolescentes escolares e de professores de uma escola pública de Porto Alegre/ RS acerca da violência no espaço escolar. Os objetivos específicos foram investigar as experiências escolares relacionadas à violência, a relação entre a violência escolar e a violência intra e extrafamiliar, e possíveis ações de enfrentamento.

\section{Método}

\section{Participantes}

Participaram do estudo 16 professores de uma escola pública de Porto Alegre, ministrantes de diferentes disciplinas de educação básica, sendo 13 mulheres e três homens. Participaram também 60 estudantes dessa mesma escola: 29 estavam cursando o $6^{\circ}$ ano do Ensino Fundamental, sendo 10 meninas e 19 meninos, com idades entre 12 e 15 anos; e 31 alunos estavam cursando o $1^{\circ}$ ano do Ensino Médio, com idades entre 15 e 18 anos. Foram convidados a participar todos os professores e todos os alunos matriculados na escola nas séries correspondentes.

\section{Contextualização}

O local de realização deste estudo foi uma escola pública localizada na zona norte de Porto Alegre, área de maior concentração populacional da cidade. Essa escola atende simultaneamente alunos do próprio bairro, bem como de bairros vizinhos e distantes, e com isto agrega estudantes de diferentes perfis socioeconômicos. No período da coleta de dados a escola tinha cerca de 840 alunos matriculados, desde a Educação infantil até o Ensino Médio e Técnico. Já nas primeiras visitas da equipe de pesquisa foi constatado histórico de situações de violência e preconceito tanto no ambiente escolar quanto no seu entorno, e a direção relatou ações já realizadas e em andamento acerca desta temática, 
demonstrando interesse e necessidade de auxílio no enfrentamento dessa situação.

\section{Instrumento}

Foi utilizada a técnica de grupo focal com o objetivo de apreender as ideias e concepções dos participantes sobre os temas propostos pelos pesquisadores para discussão. A técnica do grupo focal possibilita o debate e interação entre os participantes de modo a promover elaborações interessantes, ideias originais e opiniões divergentes sobre o tema em foco (Carey, 1994).

\section{Procedimentos}

Este artigo derivou do projeto de pesquisa intitulado Violência e Preconceito na Escola, que foi realizado com a parceria entre o Conselho Federal de Psicologia (CFP), Associação Brasileira de Ensino de Psicologia (ABEP), Associação Brasileira de Psicologia Escolar e Educacional (ABRAPEE), Federação Nacional dos Sindicatos de Psicólogos (FNSP) e dez universidades federais das cinco regiões do país. O recorte de dados utilizado neste estudo refere-se apenas aos grupos realizados na escola de Porto Alegre/RS.

Inicialmente, foram realizadas visitas para contato da equipe de pesquisa com a direção e a coordenação da escola, momento em que foi possibilitado o acesso aos documentos oficiais da escola, bem como o acompanhamento da rotina da instituição. Todos os grupos focais aconteceram em salas na própria escola, com uma duração média de uma hora e trinta minutos cada. Os grupos foram coordenados pelos pesquisadores, que apresentavam os tópicos a serem discutidos e promoviam a participação dos presentes, visando a ampla discussão das temáticas. $O$ áudio das coletas foi gravado por no mínimo três gravadores digitais localizados em diferentes pontos da sala, e cada uma das gravações foi transcrita para posterior análise.

Para a realização dos grupos, os alunos foram divididos conforme a etapa de escolarização ( $6^{\circ}$ ano do Ensino Fundamental e $1^{\circ}$ ano do Ensino Médio) e os professores formaram outro grupo. Os grupos foram orientados por um roteiro semiestruturado que incluía tópicos específicos a serem discutidos, como experiências positivas e negativas no âmbito escolar, conceituação e situações de violência e modos de enfrentamento da violência escolar. Os roteiros eram similares, sendo que o dos alunos focava em suas próprias vivências e o dos professores também possuía questões sobre a percepção destes acerca da experiência discente. Após a realização de cada grupo focal, a equipe de pesquisa promovia um debate apenas entre seus membros, denominado "Registro a quente", para trocar impressões sobre a atividade realizada. Esse registro permitiu a troca de informações entre os pesquisadores e evitou a perda das percepções imediatas destes acerca do funcionamento do grupo, linguagem não-verbal e discussões que haviam se dado no espaço de pesquisa.

\section{Considerações Éticas}

Os participantes foram informados sobre os objetivos e o método da pesquisa, sobre o sigilo e a possibilidade de deixarem de participar dos grupos a qualquer momento. A direção da escola concordou com a participação no estudo e assinou o Termo de Concordância da Instituição. Após o convite aos alunos das turmas selecionadas, foi obtido o Termo de Consentimento Livre e Esclarecido dos pais ou responsáveis, assim como o Termo de Assentimento dos adolescentes, para participação nos grupos focais. Os professores que participaram do grupo focal de professores também assinaram um Termo de Consentimento Livre e Esclarecido. O projeto foi aprovado pelo Comitê de Ética da UFMT, coordenadora do projeto maior, e houve aprovação no Comitê de Ética do Instituto de Psicologia da UFRGS.

\section{Análise dos dados}

Num primeiro momento, os dados de cada grupo foram analisados separadamente. Posteriormente, os dados e análises produzidas foram discutidos de forma integrada. $\mathrm{O}$ material obtido foi submetido à análise de conteúdo (Bardin, 1977) para que se determinassem as percepções dos diferentes participantes acerca da violência e das experiências no ambiente escolar, através de procedimentos sistemáticos e objetivos de descrição do conteúdo das discussões, envolvendo o levantamento de eixos de análise e interpretação dos resultados por categorias temáticas. Foram selecionados trechos de fala que remetiam tanto às causas explicativas da violência na escola quanto ao relato das experiências vivenciadas pelos participantes. Observou-se a recorrência das temáticas no conjunto das falas, sendo essa recorrência interpretada como representações dos participantes em relação ao tema estudado. Os dados foram triangulados a partir dos três grupos focais (com diferentes participantes, em diferentes posições dentro da escola) e do "Registro a quente" realizado pelos pesquisadores. Essa triangulação de dados em pesquisa qualitativa é fundamental para a compreensão de fenômenos multideterminados e contribui para a validade externa da pesquisa (Minayo, 2005).

\section{Resultados e Discussão}

Serão apresentados os resultados e a discussão acerca das percepções e concepções acerca da violência no espaço escolar, sistematizadas em quatro grandes categorias, definidas a posteriori: (a) Violência entre pares, (b) Violência entre alunos e professores, (c) Violência extramuros, e (d) Ações de enfrentamento. O comportamento de cada um dos grupos foi bastante diferenciado, o que influenciou no tipo 
de assunto explorado e debatido pelos participantes da pesquisa. Os alunos do $6^{\circ}$ ano do Ensino Fundamental falaram mais sobre as próprias experiências e sobre as agressões entre colegas, enquanto que entre os alunos do $1^{\circ}$ ano do Ensino Médio a discussão se centrou mais sobre as ações da direção e dos professores após a ocorrência das situações violentas. Os professores falaram sobre a violência sofrida de forma direta, pelos alunos ou direção, e de forma indireta, quando são afetados pelas agressões entre os adolescentes. Para análise foram consideradas tanto as diferenças entre os grupos (alunos e professores) quanto os pontos que os aproximam. Os trechos de fala estão identificados conforme o grupo que o participante fez parte ( $P$ - Professor, EF - aluno do Ensino Fundamental, e EM - aluno do Ensino Médio).

\section{Violência entre pares}

Esta categoria refere-se aos relatos tanto de alunos quanto de professores em relação a agressões perpetradas por alunos contra colegas, no ambiente da escola. A violência recorrente entre estudantes, seja verbal ou física, foi um ponto comum de discussão em todos os grupos. Os estudantes do $6^{\circ}$ ano relataram situações de violência física entre eles, inclusive com o uso de armas brancas (tesoura/estilete), mas centraram seus relatos nos casos de xingamento ou exclusão baseados em características que diferenciam os colegas (fenótipo/sexualidade). Os alunos do Ensino Médio não falaram muito sobre situações de violência física, mas sim sobre preconceito entre colegas. Os professores relataram perceber grande incidência de violência verbal entre os alunos, inclusive já naturalizada pelos adolescentes.

Nos grupos, tanto professores quanto alunos apresentaram relatos de casos de violência física entre os alunos, como expresso nos trechos que seguem: "Eu chamo no soco" (EF), "Não, se for do meu tamanho, um pouco maior que eu chamo na paulada" (EF), "Eu vou na mão" (EF), "Toda lanhada, ficou em carne viva. Que ela passou as unhas, sabe?" $(\mathrm{P})$, "Foi com bastante violência, foi horrível" $(P)$. A violência não se limita aos socos ou uso das mãos, mas também houve descrições de agressões com objetos, ocorridas dentro do espaço da escola: "Ah eu não, quando eu não tenho canivete eu tenho uma tesoura!"(EF), "Canivete não, só tesoura. Pra brigar. Um estilete" (EF), "Ela ficou toda marcada. Não consegue vir para a escola mais" (P), "Aí eu fiz ela voltar, daí eu me grudei no cabelo dela e ela começou... Só que, aí deu mais uma burocracia porque eu tava com um canivete pra dar nela" (EF). A exposição à violência física em escolares é muito explorada em pesquisas tanto no Brasil quanto no exterior. Um estudo em escolas portuguesas (Lourenço \& cols., 2009), realizado com 3.891 alunos identificou que $36,4 \%$ dos participantes já haviam sofrido agressão física duas ou mais vezes na escola. Os resultados de outra pesquisa realizada em Santiago (Chile) com a participação de 2111 estudantes indicaram que 40,7\% dos alunos se envolveram em conflitos com agressão física no ano anterior à pesquisa (Rudatsikira, Muula, \& Siziya,
2008). Os resultados da Pesquisa Nacional da Saúde do Escolar (IBGE, 2013) indicam que no Brasil 10,6\% dos estudantes de escolas públicas e $8,8 \%$ dos alunos de escolas privadas relataram terem sofrido alguma agressão física nas dependências da escola no ano anterior à pesquisa, resultando em lesões e ferimentos.

Os adolescentes retrataram as situações que envolvem vitimização psicológica (bullying, segundo a denominação deles), expressa através de apelidos, xingamentos ou exclusão. A não aceitação das diferenças em relação ao fenótipo ou comportamento dos colegas foi expresso nos seguintes trechos: "Ele tinha vergonha de mostrar o cabelo dele porque ficam folgando nele" (EF), "Ficavam me chamando de cara pálida, de cara de peixe morto...e é muito ruim isso" (EF). Esses relatos foram frequentemente seguidos de risadas pelos alunos, e a percepção da equipe de pesquisa foi de que esse tipo de violência estava naturalizado entre eles, a ponto de ser considerado engraçado, situação "normal" pela qual todos estão ou já estiveram sujeitos no ambiente escolar. A violência psicológica pode ter sido naturalizada na rotina escolar, mas é uma preditora da violência física (Maia, Araújo, \& Santos Júnior, 2012), além de impactar o estado psicológico das vítimas, transformando a escola em local de exclusão e degradação social (Santos \& Rodrigues, 2013).

Os adolescentes citaram também situações de preconceito em relação à orientação sexual: “... que nem tem um guri que ele é gay e ficam folgando nele" (EM), "Gera um preconceito. Porque às vezes os guris não chegam perto por medo de falarem mal deles também" (EM), "Por causa do jeito de falar dele... ele fica se pegando nos homens" (EF), "Eu não gosto muito de gay também" (EF), "Aqui tem uma guriazinha que tem o cabelo curtinho e ela (...) aí ficam chamando ela de homem" (EF). A homofobia tem se expressado nas escolas por meio de agressões físicas e verbais a que estão sujeitos os estudantes que não se adequam à heteronormatividade (Dinis, 2011). Também a omissão dos temas que incluem a diversidade sexual nos currículos escolares pode se constituir em violência (Seffner, 2011), pelo fato de que a negação dessa pluralidade não cria espaço para a discussão, compreensão e possibilidade de aceitação e respeito à diferença pelos estudantes e comunidade escolar.

\section{Violência entre alunos e professores}

Os relatos de violência perpetrada por alunos contra professores foram abordados essencialmente no grupo focal formado por docentes, que citaram repetidamente situações de conflitos com alunos na sala de aula: "E eu disse assim: "Chega! Chega! Eu não aguento mais". Puxei as minhas coisas e saí da sala. Não deu mais" (P), "O problema é que descambou para uma coisa um pouco mais agressiva, né. Houve, infelizmente, uma agressão por parte da aluna" (P), "Foi com uma aluna nossa, que foi bem difícil de lidar, que ela desrespeitou ela demais em sala de aula" (P). Os relatos de violência verbal contra professores foram mais frequentes, e indicam ocorrência de conflitos próprios da sala de aula. 
Outras pesquisas realizadas com estudantes e professores também encontraram relatos de violência verbal recorrente contra os docentes em sala de aula (Melo \& cols., 2011). Em outro estudo que analisou a violência contra os docentes, $76,5 \%$ dos professores participantes relatou sofrer insulto verbal por alunos, sendo que $20,6 \%$ responderam que essa agressão é diária (Levandoski, Ogg, \& Motriz, 2011).

Os relatos dos professores referem-se também à dificuldade para trabalhar após uma situação de conflito e sobre o quanto esses casos de violência afetam a rotina de trabalho: "Para enfrentar de frente um aluno, para depois ter que voltar para aquela sala é complicado." $(P),(P)$, , $A$ gente não tem os setores, não tem apoio." (P). A discussão sobre a sensação de desvalorização do trabalho docente também foi recorrente: "Tá muito difícil dar aula hoje em dia, né. Por causa da falta de limites, da falta de respeito dos alunos" (P), "Já estava, inclusive, pensando em largar o magistério porque estava muito difícil trabalhar" $(\mathrm{P})$, "É muito chato porque tu é professor, tu tá trabalhando. Se tu não é respeitado pelos teus alunos, sabe..." (P). Esses sentimentos de desvalorização profissional e de solidão nas situações de conflito com alunos podem se refletir inclusive em manifestações de enfermidades psicossomáticas e afastamentos do trabalho (Souza, 2012) até o abandono da carreira docente (Scheibe, 2010), considerações também manifestadas pelos participantes. A percepção negativa em relação à qualidade de vida está vinculada à saúde dos professores e às condições do ambiente e da organização do trabalho docente (Kappel, Gontijo, Medeiros, \& Monteiro, 2014). A insatisfação, o desgaste mental e o sofrimento no trabalho, expressos através de reclamações e pessimismo, foram identificados também em outros estudos realizados com professores no Brasil (Castro \& Souza, 2012; Paula, Kodato, \& Dias, 2013), e indicam tanto a falta de apoio ao docente na sua prática quanto a vitimização recorrente por violência direta ou indireta no ambiente profissional.

\section{Violência extramuros}

Nessa categoria estão inclusas as discussões das violências que ocorrem para além dos muros da escola, mas que repercutem nesse local - tanto relatos sobre violência comunitária quanto intrafamiliar, desde que o contexto social da escola tem influência nos acontecimentos internos dessa instituição (Cunha, 2014). Assim, a violência nas escolas é um fenômeno atravessado por outras formas de violências sociais (Araújo, Coutinho, Miranda, \& Saraiva, 2012). Nos grupos, tanto os alunos quanto os professores relataram diversas situações de violência comunitária, às quais estão sujeitos no entorno da escola: "É, eu já fui assaltada. Acontece de roubarem celular" (EM), "Acontece de assaltarem de noite. Já roubaram um tênis de setecentos e pouco do meu irmão" (EF), "Tenho medo de ser assaltado" (EF), "É, eu já fui assaltada" (EF), "O cara tava lá com a mulher dele e chegaram uns caras e deram pipoco (tiro) nele" (EM). A violência que ocorre fora da escola, na comunidade, como explicitada por essas falas, pode relacionar-se também às ocorrências em espaço escolar, promovendo um espaço educativo mais violento (Cocco \& Lopes, 2010). Vizinhanças mais violentas podem acarretar então em aumento dos índices de ocorrências violentas nas escolas nelas inseridas (Stelko-Pereira \& Williams, 2013), como sugerido pelos participantes nos grupos.

Os professores relataram perceber violências sofridas pelos alunos também em suas famílias, e acreditam que esse tipo de abuso afeta o comportamento e a aprendizagem dos adolescentes, como expresso nas seguintes falas: "É que o nosso aluno, a grande maioria, assim, da tarde, ele não consegue nem as necessidades básicas. Então, aí que começam as desestruturas." (P), "Essa é a realidade de muitos alunos aqui. Eles não têm limite em casa e eles não tem carinho em casa" $(P)$, "Eles sofrem violência até em casa" $(\mathrm{P})$, "Violência doméstica tem, até abuso" $(\mathrm{P})$, "São os pais que falam assim também com eles, né. Eles têm também pais que são da droga" (P6). Outra pesquisa realizada com professores indica dados semelhantes, demonstrando que reconhecem a família como sendo determinante no comportamento dos filhos através da transmissão de princípios básicos de formação de caráter e de apoio à formação cidadã, entretanto as famílias não estariam cumprindo sua função de forma adequada, sendo permissivas e omissas com relação aos problemas dos jovens, transferindo essa responsabilidade para a escola (Galinkin, Almeida, \& Anchieta, 2012).

Essa percepção dos professores acerca da vitimização dos alunos em suas famílias é relevante, pois outras pesquisas já identificaram relações entre violência intrafamiliar e escolar. Um estudo longitudinal norte-americano (Finkelhor, Ormrod, \& Turner, 2007) indicou que as crianças que sofrem violência doméstica são mais frequentemente alvo de violência na escola e na comunidade. Essa descrição de situações de violência, incluindo-se as de negligência, associada à violência comunitária relatada em todos os grupos, pode ser percebida como um dos fatores que podem estar associados aos diversos relatos de agressões dentro do espaço escolar apresentados em todos os grupos. A escola pode estar funcionando como um espaço de produção e reprodução da violência em consonância com a sociedade em que está inserida (Silva, 2013).

\section{Ações de enfrentamento}

Nesta categoria estão reunidos os relatos dos participantes que indicam tanto sua compreensão em relação à responsabilização pelas violências ocorridas na escola quanto as possíveis ações de enfrentamento que seriam efetivas para evitar que novas agressões ocorressem. As falas foram inicialmente de responsabilização de outros pelas ocorrências violentas, com a atribuição da culpa pela violência que ocorre no ambiente escolar tanto para a direção da escola quanto para as famílias dos estudantes. Entretanto, o discurso final de todos os grupos voltou-se para a necessidade de envolvimento de todos os atores da escola para o 
enfrentamento da violência, e não foi dado somente enfoque punitivo em relação aos alunos ou aos professores.

As críticas para com as ações da direção da escola referiram-se essencialmente à apatia e tempo de resposta nos casos de violência. "Eles esperam acontecer alguma coisa grave para tomar uma atitude" (EF), "A falta de uma postura, de repente, um pouco mais rígida da direção." $(\mathrm{P})$, "A atitude da direção porque quando a gente vai lá eles não escutam, eles fingem que escutam e acho que eles não resolvem nada" (EF), "Depois que acontece eles vão lá e dão um jeito" (EM). Mostra-se necessária a formação dos professores e funcionários da escola para que sua presença sirva como proteção aos estudantes, evitando que as vítimas revidem as ofensas sofridas, unam-se a gangues ou ainda usem a violência como norma social (Stelko-Pereira, Albuquerque, \& Williams, 2012). É difícil que os estudantes consigam reconhecer e enfrentar situações de intimidação na escola sem o apoio de funcionários ou professores (Nascimento \& Menezes, 2013). Por outro lado, esse auxílio do professor, por meio do incentivo do diálogo entre os envolvidos, pode tanto ajudar a solucionar a situação como contribuir para que os alunos desenvolvam novas estratégias de resolução de conflitos (Leme \& Carvalho, 2012).

Os alunos do grupo do ensino médio pontuaram por diversas vezes o pedido deles à direção no sentido de exigir mudança de atitudes por parte da equipe diretiva: "Agora no fim do ano que o colégio começou a tomar ordem, porque os alunos fizeram uma reunião com eles [direção] pra que colocasse uma ordem, que se não ia fazer manifestação, colocar cadeado no colégio" (EM), "Agora mudou porque tiveram várias reuniões que os alunos organizaram pra falar com a direção, antes tua ia falar lá na direção e não tinha ninguém" (EM). Considerando-se a formação integral do sujeito, para além da obtenção de conhecimentos formais, se faz necessária a valorização da participação ativa dos estudantes não apenas nos processos pedagógicos, mas também na construção de modos de resolução de conflitos nas relações sociais escolares (Bispo \& Lima, 2014). Segundo os alunos e os professores participantes deste estudo, a solução de conflitos e a diminuição dos índices de violência passariam pela compreensão de justiça nas relações sociais da escola, ou seja, por exigências comuns a todos os membros da comunidade e pela escuta efetiva dos anseios coletivos. A ação dos alunos, de se fazer ouvir pela direção, reflete o quanto ações coletivas por parte de todos os atores poderiam ser potencializadoras do trabalho da gestão escolar, que tomaria conhecimento das demandas de toda a escola (Botler, 2013). Entretanto, apesar do direito de participação de todos (alunos, professores, pais, direção) nas decisões nas escolas públicas, os sujeitos por vezes não reconhecem essa condição e não se sentem autorizados a construir uma cultura democrática. O discurso social que exige das escolas mais rigidez disciplinar (presente também nos grupos, na exigência de ações mais efetivas da direção), também atua nessa desautorização da experimentação de modalidades mais democráticas de se compreender disciplina, educação e participação.
Finalmente, os participantes falaram sobre a importância da implicação de toda a comunidade escolar para que a as situações de violência possam ser evitadas ou solucionadas: "A escola poderia dar mais liberdade de expressão" (EF), "se uma escola é organizada, se funciona tudo direito como tem que ser e é espelho para os alunos, esse tipo de situação não acontece" (P), "Eu acho que a gente tem que tentar resolver aqui e que tem que ter respeito" (P), "Quando a gente passa uma insegurança para eles, uma não certeza do horizonte, eu acho que isso gera muito mais [violência]" $(\mathrm{P})$, "E tem que haver o diálogo porque são muitas pessoas diferentes, com histórias diferentes, com momentos diferentes." (P), "Porque tu precisa desde o professor, do aluno da manhã, do aluno da tarde. Os alunos vão ver isso de uma outra forma e, indiretamente, todo mundo vai ter vontade de estar ali naquele momento" $(\mathrm{P})$. O envolvimento de toda a comunidade na resolução de conflitos e na prevenção à violência são fatores sustentados por estudos que indicam que as escolas menos violentas são aquelas onde a direção é mais presente e confiável e as relações são mais democráticas (Bueno \& Sant'Ana, 2011; Kappel \& cols., 2014). A organização e a autoridade tanto dos professores quanto da direção da escola são relevantes, pois são determinantes na forma de resolução das situações violentas que ocorrem nesse espaço, e inclusive é possível que o aumento da ocorrência de violência escolar deva-se também à forma como as agressões e conflitos são manejados por esses sujeitos (Leme \& Carvalho, 2012).

\section{Considerações Finais}

Os relatos dos estudantes e professores participantes revelaram o quão multifacetada a violência escolar se apresenta e os desafios no seu enfrentamento. Os resultados indicam que a violência externa à escola, seja comunitária ou familiar, também é percebida como um dos fatores que interfere na rotina escolar. $\mathrm{O}$ uso de xingamentos e a presença de preconceito e agressões como recurso comunicativo entre os estudantes e professores pode ser percebido também como um uso instrumental da violência, quando o conflito não encontra outros canais de manifestação que poderiam ser propiciados pela instituição escolar através de ações democráticas de participação dos adolescentes nas decisões que os afetam. Ou seja, o problema talvez não esteja na ausência de consenso e consequente ocorrência de conflito entre os atores da escola, mas sim nas formas que esse conflito consegue se manifestar desde que não há escuta democrática na escola: apenas através da violência física e psicológica (Zaluar \& Leal, 2001).

Compreendendo-se a violência estabelecida nas relações sociais na escola, torna-se evidente a importância de ações da direção da escola e dos professores e funcionários no sentido de auxiliar os alunos envolvidos a reconhecerem e solucionarem as situações de conflito. Entretanto, também os professores relataram carecer de formação e apoio para que consigam atuar de forma efetiva na prevenção e reso- 
lução das situações violentas. As manifestações de violência diferem de uma instituição escolar para outra, então as estratégias de prevenção devem ser pensadas para cada escola, com suas especificidades. O apoio e a participação de toda a comunidade escolar, com escuta de todos e divisão de responsabilidades, podem ser estratégias exitosas. Inclusive, a democratização da gestão da educação e das instituições educativas através da participação de toda a comunidade escolar foi prevista na Conferência Nacional de Educação (Ministério da Educação, 2010), e consta no Plano Nacional de Educação, visando a efetivação das políticas públicas de acesso e permanência de crianças e adolescentes nas escolas.

Os dados obtidos neste estudo indicando a ocorrência de múltiplas violências no espaço escolar reforçam o quanto o reconhecimento dos adolescentes como sujeitos de direitos é essencial, através da desnaturalização da vitimização desse grupo tanto por violência doméstica quanto comunitária, bem como o desenvolvimento de políticas de proteção e de promoção de cidadania para os jovens (UNICEF, 2012b). A compreensão da violência escolar como uma forma de manifestação de uma violência estrutural, que confronta uns indivíduos contra outros, aponta para a necessidade de uma resposta de resistência advinda da própria comunidade vitimada (Minayo, 1994). O espaço escolar deve ser retomado como um local de proteção aos direitos da infância e adolescência, e com essa finalidade é imperativa a implementação, nas próprias escolas, de projetos de intervenção que focalizem as relações sociais entre os adolescentes e a formação dos professores e equipe diretiva para ação efetiva nos casos de violência escolar. Outras pesquisas devem ser realizadas a fim de se compreender cada vez mais a complexidade da manifestação da violência nas escolas e possibilitar seu enfrentamento e prevenção. Sugere-se o desenvolvimento de novos estudos que investiguem a ocorrência de violência escolar, com alunos, professores e também com os gestores tanto de escolas públicas quanto privadas. Novos desenhos metodológicos, como entrevistas individuais e estudos longitudinais podem contribuir para a compreensão tanto das formas de manifestação quanto para o desenvolvimento de formas de enfrentamento das violências.

\section{Referências}

Abramovay, M. (2002). Escola e violência. Brasília: UNESCO Brasil. Recuperado: 10/10/2015. Disponível: http://unesdoc.unesco.org/ images/0012/001287/128717por.pdf

Araújo, L. S., Coutinho, M. P. L., Miranda, R. S., \& Saraiva, E. R. A. (2012). Universo consensual de adolescentes acerca da violência escolar. Psico-USF, 17(2), 243-251.

Bardin, L. (1977). Análise de conteúdo. Lisboa: Edições, 70.

Benetti, S. P. C, Schwartz, C., Soares, G., Macarena, F., \& Patussi, M. (2014). Psychosocial adolescent psychosocial adjustment in Brazil - perception of parenting style, stressful events and violence. International Journal of Psychological Research, 7(1), 40-48. Recuperado: 10/10/2015. Disponível: http:// www.scielo.org.co/scielo.php?script=sci_arttext\&pid=S2011$20842014000100005 \&$ Ing=en\&tIng=en

Bispo, F. S., \& Lima, N. L. (2014). A violência no contexto escolar: uma leitura interdisciplinar. Educação em Revista, 30(2), 161-180.

Botler, A. M. H. (2013). Cidadania e justiça na gestão escolar nas escolas públicas e privadas. Perspectiva, 31(1), 317-336. Recuperado: 25/07/2015. Disponível: https://periodicos.ufsc.br/ index.php/perspectiva/article/view/25368

Braga, L. L. \& Dell'Aglio, D. D. (2012). Exposição à violência em adolescentes de diferentes contextos: família e instituições. Estudos de Psicologia, 17(3), 413-420.

Bueno, F. A. \& Sant'ana, R. B. (2011). A experiência geracional na fala de alunos de escola pública: a questão da autoridade docente. Revista Brasileira de Estudos Pedagógicos, 92(231). Recuperado: 24/09/2015. Disponível: http://www.emaberto.inep. gov.br/index.php/RBEP/article/view/1805

Carey, M. A. (1994). The group effect in focus group: planning, implementing and interpreting focus group research. Thousand Oaks: Sage.

Castro, R. E. F. D., \& Souza, M. A. D. (2012). Efeitos da agressividade infantil para o sofrimento psíquico de professores em diferentes momentos de carreira. Estudos de Psicologia (Natal), 17(2), 265-274.

Cocco, M., \& Lopes, M. J. M. (2010). Violência entre jovens: dinâmicas sociais e situações de vulnerabilidade. Revista Gaúcha de Enfermagem, /1), 151-9.

Cunha, M. B. (2014). Possíveis relações entre percepções de violência dos alunos, clima escolar e eficácia coletiva. Educação e Pesquisa, 40(4), 1077-1092.

Debarbieux, É. (2001). A violência na escola francesa: 30 anos de construção social do objeto (1967-1997). Educação e Pesquisa, 27(1), 163-193.

Dinis, N. F. (2011). Homofobia e educação: quando a omissão também é signo de violência. Educar em Revista, (39), 39-50.

Finkelhor, D., Ormrod, R. K., \& Turner, H. A. (2007). Re-victimization patterns in a national longitudinal sample of children and youth. Child Abuse \& Neglect, 31, 479-502. Recuperado: 10/10/2015. Disponível: $\quad$ http://www.sciencedirect.com/science/article/pii/ S014521340700083X

Fonseca, F. F., Sena, R. K., Santos, R. L., Dias, O. V., \& Costa, S. M. (2013). As vulnerabilidades na infância e adolescência e as políticas públicas brasileiras de intervenção. Revista Paulista de Pediatria, 31(2), 258-264. 
Forlim, B. G., Stelko-Pereira, A. C., \& Williams, L. C. A. (2014). Relação entre bullying e sintomas depressivos em estudantes do ensino fundamental. Estudos de Psicologia (Campinas), 31(3), 367-375.

Galinkin, A. L., Almeida, A. M. O., \& Anchieta, V. C. C. (2012). Representações sociais de professores e policiais sobre juventude e violência. Paidéia (Ribeirão Preto), 22(53), 365-374.

Grossi, P. K., \& Santos, A. M. (2009). Desvendando o fenômeno bullying nas escolas públicas de Porto Alegre, RS, Brazil. Revista Portuguesa de Educação, 22(2), 249-265. Recuperado: 10/10/2015. Disponível: http://www.scielo.gpeari.mctes.pt/scielo. php?script=sci_arttext\&pid=S0871-91872009000200011\&lang=pt

Grossi, P. K., \& Santos, A. M. (2012). Bullying in Brazilian schools and restorative practices. Canadian Journal of Education, 35(1), 120-136. Recuperado: 10/09/2015. Disponivel: http://www.cje-rce. ca/index.php/cje-rce/article/view/697

IBGE. (2013). Pesquisa Nacional de Saúde do Escolar. Rio de Janeiro: Ministério do Planejamento e Gestão. Recuperado: 01/10/2015. Disponível em http://www.ibge.gov.br/home/estatistica/populacao/ pense/2012/pense_2012.pdf

Kappel, V. B., Gontijo, D. T., Medeiros, M., \& Monteiro, E. M. L. M. (2014). Enfrentamento da violência no ambiente escolar na perspectiva dos diferentes atores. Interface (Botucatu) 18(51), 723-735.

Leme, M. I. D. S. \& Carvalho, A. M. (2012). Opinião dos professores e resolução de conflitos por pré-adolescentes. Nuances: estudos sobre Educação, 23(24), 55-77.

Levandoski, G., Ogg, F., \& Cardoso, F. L. (2011). Violência contra professores de Educação Física no ensino público do Estado do Paraná. Motriz Revista de Educação Física (Impressa), 17(3), 374-383.

Lourenço, L. M., Pereira, B., Paiva, D. P., \& Gebara, C. (2009). A gestão educacional e o bullying: um estudo em escolas portuguesas. Revista Interaç̧ões, (13), 208-228. Recuperado: 10/10/2015. Disponível: http://repositorium.sdum.uminho.pt/ handle/1822/16927

Maia, L. D. L. Q. G. N., Araújo, A., \& Santos Júnior, A. D. S. (2012). O entendimento da violência escolar na percepção de adolescentes. Revista Médica de Minas Gerais, 22 (2), 166-173. Recuperado: 10/10/2015. Disponível: http://www.rmmg.org/artigo/ detalhes $/ 98$

Melo, M. C., Barros, É. N., \& Almeida, A. M. (2011). A representação da violência em adolescentes de escolas da rede pública de ensino do Município do Jaboatão dos Guararapes. Ciência \& Saúde Coletiva, 16(10), 4211-4220.
Minayo, M. C. (2005). Conceito de avaliação por triangulação de métodos. Em M. C. Minayo, S. G. Assis, \& E. R. Souza (Eds), Avaliação por triangulação de métodos. Abordagem de programas sociais (pp. 19-51). Rio de Janeiro: Fiocruz.

Minayo, M. D. S. (1994). A violência social sob a perspectiva da saúde pública. Cadernos de Saúde Pública, 10 (1), 7-18.

Ministério da Educação. (2010). Construindo o Sistema Nacional Articulado de Educação: O Plano Nacional de Educação, suas Diretrizes e Estratégias de Ação. Brasília, DF: Autor. Recuperado: 10/08/2015. Disponível: http://portal.mec.gov.br/arquivos/pdf/ conae/documento_referencia.pdf

Nascimento, A. M. T. \& Menezes, J. A. (2013). Intimidações na adolescência: expressões da violência entre pares na cultura escolar. Psicologia \& Sociedade, 25 (1), 142-151. d

Paula, A. D. S. D., Kodato, S., \& Dias, F. X. (2013). Representações sociais da violência em professores da escola pública. Estudos Interdisciplinares em Psicologia, 4 (2), 240-257. Recuperado: 10/11/2015. Disponível: http://pepsic.bvsalud.org/scielo. php?pid=S2236-64072013000200008\&script=sci_arttext

Ristum, M. (2010). Violência na escola, da escola e contra a escola. Em Assis, S.G., Constantino, P., \& Avanci, J.Q. (Orgs.), Impactos da violência na escola: um diálogo com professores (PP. 65-93). Rio de Janeiro: Fiocruz.

Rocha, K. D. M. M., de Farias, G. M., Gurgel, A. K. C., Costa, I. K. F., Freitas, M. C. D. S., \& de Souza, A. A. M. (2012). Violência na escola vivida por professores, funcionários e diretores. Revista da Rede de Enfermagem do Nordeste, 13(5), 1034-1044. Recuperado: 12/01/2016. Disponível: http://www.revistarene.ufc. br/revista/index.php/revista/article/view/1161/pdf

Rudatsikira, E., Muula, A. S., \& Siziya, S. (2008). Prevalence and correlates of physical fighting among school-going adolescents in Santiago, Chile. Revista Brasileira de Psiquiatria, 30(3), 197-202.

Santos, J. M., \& Rodrigues, P. J. M. (2013). O diálogo como possibilidade de mediação da violência na escola. Práxis Educativa, 8(1), 273-294. Recuperado: 12/01/2016. Disponível: http://dialnet.unirioja.es/servlet/articulo?codigo $=4383879$

Scheibe, L. (2010). Valorização e formação dos professores para a educação básica: questões desafiadoras para um novo plano nacional de educação. Educação \& Sociedade, 31 (112), 981 1000.

Seffner, F. (2011). Um bocado de sexo, pouco giz, quase nada de apagador e muitas provas: cenas escolares envolvendo questões de gênero e sexualidade. Revista Estudos Feministas, 19 (2), 561 572. 
Silva, M. (2013). A violência da escola na voz de futuros professores: uma probabilidade da produção da cultura da violência em ambientes escolares?. Educação em Revista, (49), 339- 353.

Souza, K. O. J. (2012). Violência em escolas públicas e a promoção da saúde: relatos e diálogos com alunos e professores. Revista Brasileira em Promoção da Saúde, 25(1), 71-79.

Stelko-Pereira, A. C., \& Williams, L. C. A. (2013). School violence association with income and neighbourhood safety. Child Abuse \& Neglect, 23, 105-123.

Stelko-Pereira, A. C., Albuquerque, P. P., \& Williams, L. C. A. (2012). Percepção de alunos sobre a atuação de funcionários escolares em situações de violência. Revista Eletrônica de Educação, 6, 376-391. Recuperado: 10/08/2015. Disponível: http://www. reveduc.ufscar.br/index.php/reveduc/article/view/277

UNICEF. (2012a). Acesso, permanência, aprendizagem e conclusão da educação básica na idade certa - Direito de todas e de cada uma das crianças e dos adolescentes. Brasília: Autor. Recuperado: 10/01/2016. Disponível: http://www.unicef.org/brazil/pt/br_oosc_ ago12.pdf

UNICEF. (2012b). Guia Municipal de Prevenção da Violência Letal contra Adolescentes e Jovens. Rio de Janeiro: Observatório de Favelas. Disponível: http://www.forumseguranca.org.br/storage/ download//cartilha-_escolas_seguras.pdf

Winsper, C., Lereya, T., Zanarini, M., \& Wolke, D. (2012). Involvement in bullying and suicide-related behavior at 11 years: a prospective birth cohort study. Journal of the American Academy of Child \& Adolescent Psychiatry, 51(3), 271-282. Recuperado: 10/10/2015. Disponível: $\quad$ http://www.sciencedirect.com/science/article/pii/ S0890856712000020

Zaluar, A., \& Leal, M. C. (2001). Violência extra e intramuros. Revista Brasileira de Ciências Sociais, 16(45), 145-164. Recuperado: 10/10/2015. Disponível: http://www.scielo.br/pdf/rbcsoc/ v16n45/4335.pdf

\section{Sobre os autores}

Jaqueline Portella Giordani (jaquelinegiordani@gmail.com)

Psicóloga pela UFRGS (2010) e Mestra em Psicologia (UFRGS - 2015). Atua como Psicóloga do Colégio de Aplicação da UFRGS desde 2011.

Fernando Seffner (fernandoseffner@gmail.com)

Graduado em Geologia (1981) e História (1987) pela UFRGS, Mestre em Sociologia (UFRGS-1995), Doutor pelo PPG em Educação da UFRGS (2003). Atualmente é Professor Associado II da Faculdade de Educação da UFRGS. É docente e orientador junto ao PPG Educação.

Débora Dalbosco Dell’Aglio (dddellaglio@gmail.com)

Psicóloga pela PUCRS (1983), Mestre (1992) e Doutora (2000) em Psicologia do Desenvolvimento pela UFRGS. É docente do PPG em Psicologia da UFRGS, orientadora de mestrado e doutorado no PPG Psicologia da UFRGS. 